\title{
Sex ratios and hormones in HLA related rheumatic diseases
}

\author{
William H James
}

\begin{abstract}
The major diseases associated with HLA-B27 (Reiter's disease, ankylosing spondylitis, acute anterior uveitis, and psoriatic arthritis) all occur much more commonly in men. Published evidence indicates that the antigen HLA-B27 is associated with high testosterone concentrations in men. Moreover, the antigen HLAB44 exerts a protective effect on one of these diseases (psoriatic arthritis), and there are external grounds for supposing that HLA-B44 indexes an antiandrogenic process.

These data are interpreted as support for the hypothesis (first adumbrated nearly 20 years ago) that HLA antigens index unusual hormone concentrations, which in turn are causally related to the diseases.

An examination of published reports suggests that sibs of probands with ankylosing spondylitis (and perhaps Reiter's disease) contain an excess of men, and that sibs of probands with rheumatoid arthritis contain an excess of women. These data lend further support to the hypothesis.
\end{abstract}

In 1972 Ivanyi et al reported that a genetic factor identical with or closely linked to the $\mathrm{H}-2$ system in the mouse participates in the control of sex hormone metabolism. ${ }^{1}$ On the basis of this finding they made a remarkable prediction: 'If the situation in histocompatibility genetics in man is analogous to that in the mouse, a great number of physiological characters and disorders may be expected to display a statistically significant association with HLA types. On the basis of the mouse model, continuous (rather than discontinuous) variation may be expected to be found in the HLA traits ...'

Over the intervening years both parts of this prediction have been confirmed. In 1973 ankylosing spondylitis and Reiter's disease were both shown to be closely associated with HLA-B27 ${ }^{2}$; other conditions (multiple sclerosis, lupus erythematosus, and various categories of arthritis) have since been shown to be less closely associated with HLA markers. In all these illnesses continuous variation in the HLA trait is apparent, as predicted.

In general, the mechanisms responsible for the associations of HLA with disease are not established, and workers have assumed that $(a)$ the HLA antigen plays no immediate part, its locus being close to disease susceptibility genes or $(b)$ the HLA antigen on the cell membrane interacts with other factors-for example, infectious agents, to produce disease or $(c)$ molecular mimicry has a role in disease development. $^{3}$

It is interesting to consider another alternative suggested by Ivanyi's prediction-namely, that HLA genes index endocrine abnormalities, which form necessary (but not sufficient) conditions for the disease. Several points are compatible with such a suggestion.

Firstly, there is direct evidence relating the testosterone concentrations of women ${ }^{4}$ and men $^{5}$ to HLA markers; moreover, testosterone concentrations of haplotype identical brothers show greater similarity than those of haplotype nonidentical brothers. ${ }^{6}$

Secondly, there are substantial heritabilities of human plasma oestrogen and testosterone concentrations in men, ${ }^{7}$ and of dehydroepiandrosterone in both sexes. ${ }^{8}$

Thirdly, a considerable amount of data has been cited to support the hypothesis that the sexes of human (and other mammalian) offspring are partially controlled by the hormone concentrations of both parents at the time of conception-high concentrations of oestrogen and testosterone favouring the births of sons, and high concentrations of gonadotrophin and progesterone favouring the births of daughters. ${ }^{9-11}$ If this hypothesis were correct then (bearing in mind the associations of HLA markers with hormone concentrations) one might expect unusual sex ratios among the sibs and offspring of probands with HLA related diseases.

Three diseases will be discussed in this context-Reiter's disease, ankylosing spondylitis, and rheumatoid arthritis. Ankylosing spondylitis and Reiter's disease have a number of features in common. As mentioned above, they are both closely associated with HLA-B27, and both are much more common in men. Additionally, genitourinary infection is common in both. 1213

Reiter's disease. Symptoms of Reiter's disease are commonly triggered by non-specific urethritis. This infection is powerfully associated with sexual activity: promiscuity is a well established risk factor for Reiter's disease. ${ }^{14} \mathrm{It}$ is not clear, however, that the infection is a necessary condition for the manifestation of the disease. So one may wonder whether Reiter's disease and the behavioural antecedents of infection are both due to high concentrations of testosterone. If this were correct one might 
expect HLA-B27 to index high concentrations of testosterone. Ollier $e t a l^{5}$ tabled mean testosterone concentrations of 138 healthy men and 71 men with rheumatoid arthritis by 12 HLA B markers. Out of $12 \mathrm{~B}$ markers the ranking of HLA-B27 was second highest in the controls and third highest in the patient sample. The combined weight of this evidence (assessed by the Haldane-Smith test ${ }^{15}$ ) is to suggest that-as expected-HLA-B27 is associated with high testosterone concentrations in men $(p \approx 0.05$, one way). This being so, one would further expect high sex ratios (men to women) in the sibs of probands with Reiter's disease. Table 1 gives data on this point. Although not statistically significant at a conventional level, the data nevertheless suggest an excess of men.

Ankylosing spondylitis This disease is associated with genitourinary pathology typically diagnosed as 'prostatitis'.13 The causes of this condition (or group of conditions) are diverse and only partially elucidated: some of them are venereally transmitted, however. ${ }^{18} 19$ So although the behavioural evidence for ankylosing spondylitis is weaker than that for Reiter's disease, one would certainly suspect an association with sexual promiscuity and hence with high testosterone concentrations and thus with

Table 1 Sexes of the sibs of probands with Reiter's syndrome

\begin{tabular}{lll}
\hline Source & Men & Women \\
\hline Kousa et al l6 $^{17}$ & 23 & 16 \\
Woodrow et al $^{7}$ & 10 & 3 \\
Totals & 33 & 19 \\
\hline
\end{tabular}

Table 2 Sexes of the sibs of probands with ankylosing spondylitis

\begin{tabular}{|c|c|c|}
\hline Source & Men & Women \\
\hline 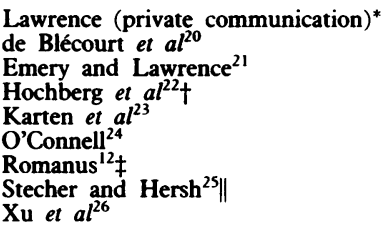 & $\begin{array}{r}103 \\
200 \\
85 \\
5 \\
68 \\
184 \\
23 \\
86 \\
21\end{array}$ & $\begin{array}{r}100 \\
201 \\
63 \\
4 \\
101 \\
110 \\
15 \\
72 \\
12\end{array}$ \\
\hline Totals & 775 & 678 \\
\hline
\end{tabular}

*The data in Dr Lawrence's private communication refer to the families reported in the abstract by Lawrence $e t$ al. ${ }^{29}$

The data cited here from Hochberg et al ${ }^{22}$ relate to their families 1 and 7.

$\ddagger$ The data of Romanus ${ }^{12}$ relate to the unaffected sibs of his seven affected sib pairs. The sexes of the unaffected sibs of his other probands are apparently not available.

The data of Hersh $e a^{30}$ are not included here, being presumed to be already contained in those of Stecher and Hersh. ${ }^{25}$

Table 3 Sexes of sibs of probands with the given disease categories

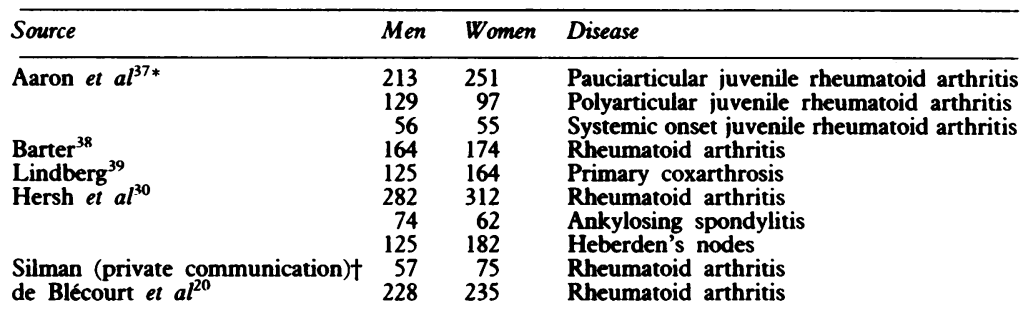

* The data of Van Kerckhove $e t a l^{40}$ are not included here, being presumed to be included in the data of Aaron et al.

tThe data of Silman refer to the unaffected sibs of his affected sib pairs. The sexes of the sibs of this other probands are not available. Dr Silman's study is reported in Silman et al. ${ }^{41}$ high sex ratios (M:F) in the families of probands with ankylosing spondylitis. Table 2 gives data on this point. There is good evidence for an excess of brothers among the sibs of probands with ankylosing spondylitis.

In none of the studies included in table 2 is it suggested that the reported numbers of brothers and sisters are the totals of sibs ever born. Instead the reported numbers comprise those living or those examined. Men have higher mortality at all ages than women and in general, men are less likely to volunteer, or make themselves available, for routine examinations, ${ }^{27} 28$ but the overall male excess exists despite these limitations.

Rheumatoid arthritis. Clinical rheumatoid arthritis affects more women than men. There is strong evidence of hormonal involvement in this disease, as witness the waxing and waning of symptoms associated with phases of women's menstrual and life cycles. The hormonal associations with rheumatoid arthritis differ for the two sexes. There can be no reasonable doubt that men with rheumatoid arthritis have unusually low testosterone concentrations. ${ }^{31-33}$ In contrast, female patients seem to have normal testosterone concentrations ${ }^{34} 35$; but it has been suggested that their oestrogen concentrations are low, this being a basis for an apparent protective effect of oral contraception. ${ }^{36}$ Bearing in mind the low testosterone (in male patients) and oestrogen (in female patients) one would expect low sex ratios $(M: F)$ in sibs of these patients. Table 3 gives the data. There certainly seems to be an excess of sisters among the sibs of probands with rheumatoid arthritis.

The three sets of data of Aaron et $\mathbf{l l}^{37}$ (shown in table 3) were compiled while probands were still young, thus largely precluding bias due to differential mortality of the sexes. The sex ratios (M:F) of the three samples show significant heterogeneity $\left(\chi_{2}^{2}=7 \cdot 6, p<0 \cdot 025\right)$. This suggests that (even bearing in mind possible ascertainment biases) either probands with pauciarticular juvenile rheumatoid arthritis have an excess of sisters or probands with polyarticular juvenile rheumatoid arthritis have an excess of brothers, or both. The various categories of juvenile rheumatoid arthritis have different HLA associations. I suggest that the biased sex ratios of their sibs reflect differing hormonal participation indexed by these HLA associations.

The three sets of data of Hersh et $a^{30}$ (table 3) were each assembled in order to calculate sib risks in respect of each of the three diseases: in other words, the numbers of brothers and sisters were not accumulated incidentally, but as an essential part of the research. These three sets of data also show significant heterogeneity between the sex ratios $\left(\chi_{2}^{2}=7 \cdot 8, p<0 \cdot 025\right)$. This suggests that one or more of the following propositions is true: $(a)$ there is an excess of sisters among the sibs of patients with rheumatoid arthritis; $(b)$ there is an excess of brothers among the sibs of patients with ankylosing spondylitis; (c) there is an excess of sisters among the sibs of probands with Heberden's nodes (osteoarthritis of the finger joints).

In table 3 all four samples of sibs of adult patients with rheumatoid arthritis show an 
excess of women. The excess is far greater than could be explained by differential mortality. In view of the fact that in all four studies familial factors were the subject of investigation one may discount volunteer bias as an explanation for the excess of women: the probands themselves were the sources of information.

Two further points are compatible with the suggestion that HLA genes index endocrine abnormalities. Firstly, in psoriatic arthritis, another HLA-B27 associated condition, a risk ratio of $7 \cdot 4$ has been suggested. ${ }^{42}$ It is interesting that these authors also suggest a risk ratio of 0.4 that is, a protective effect, of HLA-B44 in this disease. As noted below, bearers of the B44 antigen have been reported to have an excess of sisters. Evidence has been cited above that HLA-B27 indexes high androgen concentrations. So there are two independent reasons to suspect that B44 indexes an antiandrogenic process. There seems sufficient evidence here to warrant consideration of antiandrogenic drugs in the treatment of psoriatic arthritis. Moreover, if B44 protects against Reiter's disease or ankylosing spondylitis then perhaps those diseases might respond to such treatment too.

Secondly, consider again the two hypothesesnamely, those linking sex ratios to hormomes, and hormones to HLA markers. If they were correct one might expect odd sex ratios in the first degree relatives of carriers of some of the antigens. The report of Van Kerckhove et $a l^{40}$ supports this suggestion. These authors classified probands with early onset pauciarticular juvenile rheumatoid arthritis according to whether they were HLA-B44 positive or not and examined the sexes of their sibs. Those probands who were positive had a significantly greater number of sisters than those who were not. For this reason, I suggest that B44 either directly or indirectly indexes an antiandrogenic process. As noted previously, this antigen protects against psoriatic arthritis, possibly for this reason.

\section{Further research}

If the above speculations seem plausible, then it might be worth considering a number of proposals.

Firstly, the hormonal profiles in HLA associated diseases should be further examined; many of the diseases are in any case known to be hormone related without the hormonal role having been elucidated.

Secondly, the sex ratios of first degree relatives of probands with these diseases should be further examined to see if they throw light on the hormonal status of their families. In particular, it would be interesting to see more data on the sexes of offspring and sibs of probands with Reiter's syndrome and ankylosing spondylitis.

Thirdly, the normal profiles associated with HLA markers should be directly investigated further. In particular, attempts should be made to correlate major histocompatibility complex class II antigens with hormone concentrations. Moreover, if, as suggested above, hormones mediate between the antigens and the diseases for which they are markers then presumably the antigens would correlate more strongly with the hormones than with the diseases. In particular, one would like to see further work on hormone concentrations of HLA-B27 carriers. Do hormone profiles discriminate between diseased and non-diseased HLA-B27 subjects, and between those with the various B27 related diseases?

Fourthly, it would be interesting to know whether in man, as in the mouse ${ }^{1}$ (and pig $^{43}$ ) testis size is related to HLA markers. If this were so it would provide impetus for the research here suggested.

Fifthly, it would be interesting to know whether (consistent with the suggestion that hormones play a central part in these diseases) men with ankylosing spondylitis or Reiter's disease are taller than other men, on the average.

Finally, a comparison of the data of Ollier $e t$ $a l^{5}$ with those of Gerencer $e t a l^{4}$ (on the associations of HLA markers with testosterone concentrations in respectively men and women) suggests that although HLA-B27 indexes high concentrations of testosterone in men, it does not do so in women. If this is correct then one would expect that HLA-B27 would not serve as a marker (or so powerful a marker) for these diseases in women. The point could readily be tested.

I am grateful to Drs J S Lawrence (of Manchester) and A J Silman (now of the University of Manchester) for providing the data cited in tables 1 and 3 .

1 Ivanyi P, Hampl R, Starka L, Mickova M. Genetic association between $\mathrm{H}-2$ gene and testosterone metabolism in mice. Nature New Biology 1972; 238: 281-2.

2 Brewerton D A, Caffrey M, Nicholls A, Walters D, Oates J K, James D C O. Reiter's disease and HL-A27. Lancet 1973; ii: 996-8

3 Schwimmbeck P L, Oldstone M B A. Molecular mimicry between human leukocyte antigen B 27 and klebsielia: consequences for spondyloarthropathies. Am $\mathrm{J} \mathrm{Med} \mathrm{1988;}$ 85 (suppl $6 A$ ): $51-3$.

4 Gerenčer M, Tajic M, Kerhin-Brkljačic V, Kastelan A An association between serum testosterone level and HLA phenotype. Immunol Lett 1982; 4: 155-8.

5 Ollier W, Spector T, Silman A, et al. Are certain HLA haplotypes responsible for low testosterone leveis in males? Dis Markers 1989; 7: 139-43.

6 Spector T D, Ollier W E R, Perry L A, Silman A J. Evidence for similarity in testosterone levels in haplotype identical brothers. Dis Markers 1988; 6: 119-25.

7 Meikle A W, Bishop D T, Stringham J D, West D W. Quantitating genetic and nongenetic factors that determine plasma sex steroid variation in normal male twins. Metabolism 1986; 35: 1090-5.

8 Rotter J I, Wong F L, Lifrak E T, Parker L N. A genetic component to the variation of dehydroepiandrosterone sulfate. Metabolism 1985; 34: 731-40.

9 James W H. The human sex ratio. Part 2: a hypothesis and a program of research. Hum Biol 1987; 59: 873-900.

10 James $W$ H. Parental hormone levels and mammalian sex ratios at birth. I Theor Biol 1989; 139: 59-67.

11 James $W \mathrm{H}$. The hypothesized hormonal control of human sex ratio at birth-an update. I Theor Biol 1990; 143: $555-64$

12 Romanus R. Pelvo-spondylitis ossificans in the male (ankylosing spondylitis, Morbus Bechterew-MarieStrümpell) and genitourinary infection. Acta Med Scand 1953; (suppl 280): 1-368.

3 Calin A. Reiter's syndrome. In: Calin A, ed. Spondylarthropathies. London: Grune and Stratton, 1984: 119-49.

4 Csonka G W. The course of Reiter's syndrome. BMJ 1958; i: $1088-90$

15 Haldane J B S, Smith C A B. A simple exact test for birth order effect. Annals of Eugenics 1947; 14: 117-24.

16 Kousa M, Lassus A, Karvonen J, Tilikainen A Aho $K$. Family study of Reiter's disease and HLA B 27 distribution. $\mathcal{F}$ Rheumatol 1977 ; 4: 95-102.

17 Woodrow J C, Treanor B, Usher N. The HL-A system in Reiter's syndrome. Tissue Antigens 1974; 4: 533-40. 
18 Kuberski T T. Ankylosing spondylitis associated with Trichomonas vaginalis infection. $\mathcal{F}$ Clin Microbiol 1981; 13: 7richo-1.

19 De Groen P C, Vukov L F. Sexual intercourse: you, me and the microbe makes three. $\mathcal{F} A M A$ 1987; 258: 1730 .

20 de Blécourt J J, Polman A, de Blécourt-Meinbersma $T$. Hereditary factors in rheumatoid arthritis and ankylosing spondylitis. Ann Rheum Dis 1961; 20: 215-20.

21 Emery A E H, Lawrence J S. Genetics of ankylosing spondylitis. $\mathcal{F}$ Med Genet 1967; 4: 239-44

22 Hochberg M C, Bias W B, Arnett F C. Family studies in HLA B27 associated arthritis. Medicine (Baltimore) 1978; 57: 463-75.

23 Karten I, DiTata D, McEwen C, Tanner M. A family study of rheumatoid (ankylosing) spondylitis. Arthritis Rheum of rheumatoid $1962 ; 5: 131-43$.

24 O'Connell D. Heredity in ankylosing spondylitis. Ann Intern Med 1959; 50: 1115-21.

25 Stecher R M, Hersh A H. Familial occurrence of ankylosing spondylitis. British fournal of Physical Medicine 1955; 18: $176-83$.

26 Xu F, Jin-Cheng W, You-Min J, Qian K. Ten families of ankylosing spondylitis. Chin Med F [Engl] 1989; 102: $709-12$

27 Rosnow R L, Rosenthal R. Volunteer effects in behavioral research. New Directions in Psychology 1970; 4: 211.

28 Lykken D T, McGue M, Tellegen A. Recruitment bias in twin research: the rule of two thirds reconsidered. Behav twin research: the rule
Genet 1987; 17: $343-62$.

29 Lawrence J S, Gellsthorpe K, Morrel G, Moll J. Genetic factors in ankylosing spondylitis. $\mathcal{J}$ Med Genet 1985; 22: 394.

30 Hersh A H, Stecher R M, Solomon W M, Wolpaw R, Hauser $H$. Heredity in ankylosing spondylitis: study of $\mathbf{5 0}$ families. Am F Hum Genet 1950; 2: 391-408.

31 Cutolo M, Balleari E, Accardo S, et al. Preliminary results of serum androgen level testing in men with rheumatoid arthritis. Arthritis Rheum 1984; 27: 958 .

32 Gordon D, Beastall G H, Thomson J A, Sturrock R D.
Androgenic status and sexual function in males with Androgenic status and sexual function in males with 1986; 60: 671-9.

33 Spector T D, Perry L A, Tubb G, Silman A J, Huskisson E C. Low free testosterone levels in rheumatoid arthritis. Ann Rheum Dis 1988; 47: 65-8.

34 Cutolo M, Balleari E, Giusti M, Monachesi M, Accardo S Sex hormone status in women suffering from rheumatoid arthritis. $\mathcal{J}$ Rheumatol 1986; 13: 1019-23.

35 Spector T D, Perry L A, Tubb G, Huskisson E C. Androgen status of females with rheumatoid arthritis. $\operatorname{Br} \mathcal{F}$ Rheumatol 1987; 26: 316-8.

36 van Zeben J, Hazes J M W, Dijkmans B A C, Vandenbroucke J P. Oral contraception protects against severe forms of heumatoid arthritis [Abstract]. Br $\mathcal{F}$ Rheumatol 1989; 28 (suppl 2): 86.

37 Aaron S, Fraser P A, Jackson J M, Larson M, Glass D N. Sex ratio and sibship size in juvenile rheumatoid arthritis ratio and sibship size in juvenile rheumat

38 Barter $\mathbf{R} \mathbf{W}$. Familial incidence of rheumatoid arthritis and acute rheumatism in 100 rheumatoid arthritics. Ann Rheum Dis 1952; 11: 39-46.

$39 \mathrm{Lindberg} \mathbf{H}$. Prevalence of primary coxarthrosis in siblings of patients with primary coxarthrosis. Clin Orthop 1986; 203 273-5.

40 Van Kerckhove C, Balakrishnan K, Levinson J E, Larson M G, Glass D N. HLA and altered sex ratios in juvenile rheumatoid arthritis sibships. Hum Immunol 1988; 22: 227-33.

41 Silman A J, Roman E, Beral V, Brown A. Adverse reproductive outcomes in women who subsequently develop reproductive outcomes in women who subsequently develo

42 Sasazuki T, McDevitt H O, Grumet F C. The association between genes in the major histocompatibility complex and disease susceptibility. Annual Review of Medicine 1977; 28 425-52.

43 Renard C, Vaiman M. Possible relationships between SLA and porcine reproduction. Reprod Nutr Dev 1989; 29: 569-76. 